\title{
Finite Element Modeling and Fatigue Life Prediction of Helicopter Composite Tail Structure under Multipoint Coordinated Loading Spectrum
}

\author{
Ao-Shuang Wan ${ }^{1}$, Yi-Geng Xu², Li-Heng Xue ${ }^{3}$, Ming-Rui Xu ${ }^{3}$, Jun-Jiang Xiong ${ }^{1 *}$ \\ 1 School of Transportation Science and Engineering, Beihang University, Beijing, 100191, People's \\ Republic of China (*, corresponding author: jjxiong@buaa.edu.cn) \\ 2 School of Aerospace, Transport and Manufacturing, Cranfield University, Cranfield, MK43 0AL, \\ United Kingdom \\ 3 China Helicopter Research and Development Institute, Jingdezhen 333001, People's Republic of \\ China
}

\begin{abstract}
This paper presents a numerical study on fatigue life prediction of helicopter composite tail structure under multipoint coordinated loading spectrum. The FE model of a full-scale helicopter composite tail structure was established and then validated with the experimental results of strain and displacement distributions. Good agreement has been achieved between simulation and experiments under two multipoint coordinated static loading conditions representing left yawing and two-point horizontal landing. A progressive damage analysis was performed on the tail structure model under multipoint coordinated spectrum loading. The predicted fatigue life of the helicopter tail structure is 64 repeated applications of the load spectrum. No element failure was predicted on the tail structure after 48 repeated applications of the load spectrum. The impact damage introduced on the left-side wall thereafter propagated after another 6 repeated applications of the load spectrum, which agrees well with experimental observations. The progressive damage analysis has been shown to be a practical engineering tool for life prediction of helicopter composite structures.
\end{abstract} KEYWORDS FE modeling; fatigue life prediction; helicopter composite structure; spectrum loading; progressive damage analysis

\section{INTRODUCTION}

Due to the light weight, high strength and high stiffness, fiber reinforced polymer composite materials have been increasingly applied in primary aircraft structures where structural integrity is an essential requirement $^{[1]}$. Such structural application needs to demonstrate reliable long-time performance of 
composites to avoid catastrophic fatigue failure. In recent decades, a large body of research has been done to probe fatigue behaviors and failure modes of composite structures. Cvitkovich et al. ${ }^{[2]}$ conducted four-point bending fatigue tests on composite skin/stringer flat coupon, and found that the delamination first initiated from matrix cracking in the bondline and then propagated to one side of the interface between the bondline and composite coupon with the increasing cyclic loading, which was followed by delamination between plies at corners. Thawre et al. ${ }^{[3]}$ carried out fatigue tests on carbon/epoxy T-joint subjected to standard load spectrum mini-FALSTAFF for fighter aircraft, demonstrating that cracks first initiated in the delta region and then propagated to the skin/flange region, causing final failure of T-joint. It has been also found that the stiffness of T-joint almost remained constant until cracks first initiated in the delta region after 10 applications of the load spectrum, and then decreased with the growth of crack. Zhang et al. ${ }^{[4]}$ tried to understand fatigue behavior and failure mode of carbon fiber reinforced composite component by fatigue tests, it has been illustrated that the delamination in the thickness transition area was the dominant failure mode, and the initiation and propagation of delamination arising from fatigue loading could result in local strain redistribute, namely, the strain in the damaged region suddenly decreased and then restored to a stable value with the increase in loading cycle. Chen ${ }^{[5]}$ performed fatigue tests on full-scale composite wind turbine blade under flap-wise bending loading, involving that the bending stiffness of composite blade decreased with the increasing cyclic loading, and the degradation trend in stiffness for composite blade was similar to that for composite materials.

Another main concern is the potentially significant dropping to fatigue strength and life of composite structure due to the impact-induced delamination events. Huang and $\mathrm{Zhao}^{[6]}$ undertook fatigue tests on post-impacted composite beams and revealed that fatigue damage growth rate of post-impacted composite beam increased, but residual strength/stiffness decreased with the increasing post-impacted damage size. Aoki et al. ${ }^{[7]}$ executed fatigue tests on hat-shape stitch reinforced stringer stiffened panel (a typical part of upper skin of lightweight composite wing) with multiple impact-induced damages under mini-TWIST spectrum loading. It has been shown that no damage growth was found over three times of design life and residual strength of the structure was verified at design limit load level, implying superior damage tolerance behavior of the structure. Tan et al. ${ }^{[8]}$ compared fatigue strengths of unstitched and selectively stitched stiffened composite structures with two post-impacted damages located at the flange and stiffener respectively. The experimental results show that the through-the- 
thickness stitching between the skin and the stiffener could effectively improve fatigue strength and damage tolerance of stiffened composite structure. Bisagni et al. ${ }^{[9]}$ fulfilled four-point bending fatigue tests on composite laminates with embedded delamination defect at the bondline, and revealed that the delamination first grew rapidly and followed by a plateau in growth rate. Liu et al. ${ }^{[10]}$ experimentally investigated the influence of delamination defect location on fatigue behavior of bonded composite joint, and involved that the defect inserted at the interface between adhesive and adherend more drastically reduced fatigue strength and life of the joint than that inserted within the adhesive bulk. Bisagni and Davila ${ }^{[11,12]}$ achieved experimental research on damage tolerance behavior of post-buckled hat-shape stringer stiffened composite structure with delamination defect at skin/stringer interface. It has been seen that although structural collapse load reduced with the increase in delamination size, the structure with the opening and growth of initial delamination could still sustain a large number of loading cycles until the delamination between skin and stringer propagated into the flange opposite to rapidly contribute to final failure of structure within several loading cycle. Akker et al. ${ }^{[13]}$ investigated the effect of hygrothermal aging on fatigue behavior of composite T-stringer stiffened panel with delamination defect at skin/stringer interface, and stated that hygrothermal aging could decreased delamination growth rate, but had no effect on residual strength and stiffness of the structure.

In order to reduce the development cost and shorten the cycle of aircraft design, it is necessary to develop and validate appropriate analytical and numerical tools for evaluating fatigue life and damage tolerance of composite structures. Finite element (FE) method has been widely applied in fatigue analysis of composite structures due to its capacity in providing detailed descriptions of stress and strain distributions. Attia et al. ${ }^{[14,15]}$ proposed a FE analysis methodology based on fracture behaviors of composite material to predict fatigue life of carbon fiber reinforced polymer (CFRP) I-beam and post-impacted CFRP I-stringer stiffened panel. The predictions correlated well with experimental results. Raimondo and Bisagni ${ }^{[16]}$ devised a FE analysis procedure based on cohesive model and "min-max load approach" to predict the delamination growth rate of single stringer stiffened composite structure with skin/stringer delamination defect under post-buckling compressive loading. A good correlation between the numerical and experimental results had been achieved. Nowadays, progressive damage analysis with the aid of FE method is available dealing with damage mechanism and fatigue life of composite structures ${ }^{[17-21]}$, in which the static failure criteria such as Hashin, Puck 
and Tsai-Wu are modified to identify fatigue failure in elements and the residual stiffness and strength models are implemented as gradual material degradation metric. Koch et $\mathrm{al}^{[22]}$ presented a progressive damage model of CFRP tension strut subjected to multi-axial cyclic loading to predict fatigue life, and the predictions had a good agreement with the experiments. Rivera et al. ${ }^{[23]}$ reported progressive damage analysis of composite thin-walled beam (TWB) under reversed fatigue loading, showing that even though the initial failure first occurred in specific layers, the overall functionality of the structure had not significantly deteriorated over a long period of cyclic loading. Caous et al. ${ }^{[24]}$ compared fatigue lives of composite wind turbine blade by using normative approach (i.e. linear Miner rule) and progressive damage model. It has been demonstrated that linear Miner rule is much more conservative for life prediction than progressive damage model, and progressive damage analysis provides vital information to understand damage mechanism of composite structure. Rayavarapu ${ }^{[25]}$ evaluated damage tolerance behavior of rotorcraft horizontal composite tail with ply drop-off under spectrum loading by using multi-scale progressive damage analysis. It has been found that fatigue damage initiated at the root of a rib at $10^{4}$ load cycles and subsequently propagated in the form of tension and compression damage of fiber and matrix as well as in-plane shear damage. Up to $2 \times 10^{7}$ load cycles, fatigue damage had not yet reached critical level to cause final failure of tail structure. From the previous review, it has been observed that most of the researches centered their attention on fatigue and damage tolerance behavior of composites from coupon to component level. However, there seems to be precious few works done on fatigue and damage tolerance behavior of composite structures at primary structure level, especially for that under spectrum loading. This paper aims to fill the gap in developing and validating the fatigue life prediction method of composites at primary structure level by progressive damage analysis of helicopter composite tail structure with impact damage under multipoint coordinated loading spectrum.

\section{FE MODELING}

\subsection{Materials and structures}

The composite tail beam composed of walls and frames connects the fuselage and inclined beam, which is a critical load-bearing structure of XX helicopter (Fig. 1). The four surrounding thin walls (top, left-side, right-side and bottom walls), stringers and frames T2 to T9 comprise the stiffened composite laminated structures. The middle and end sidewalls are composite honeycomb sandwich structures. Frames T1, T10 to T13 and joints are metal structures. The mechanical properties of metal, 
composite and honeycomb core materials in the helicopter tail structure are listed in Tables 1 to 3. Note that 3238A/CF3052 in Table 2 is the CFRP woven composite material, and 3238A/CCF300 is the CFRP unidirectional (UD) composite material. The stacking sequences of composite parts in tail beam structure are listed in Table 4 .

\subsection{FE modeling}

According to the geometry and dimensions of XX helicopter composite tail structure (Fig. 1), the mechanical properties of materials (Tables 1 to 3) and the composite stacking sequence (Table 4), the FE model of helicopter tail beam was generated with HYPERMESH software. In order to simulate the actual loading condition, the FE models of load transfer segment and inclined beam connected with the composite tail beam were also established in HYPERMESH. Shell elements (S3 and S4R) were employed for the walls and Solid element C3D8R was implemented for the stiffeners. The total number of nodes and elements are 1086283 and 977011 , respectively.

Fig. 2a shows the FE model of top wall in the tail beam, which is stiffened with three stringers between frames T1 and T12 by using tie constraint as the connection is achieved by co-curing process during manufacturing. Fig. $2 \mathrm{~b}$ demonstrates the FE model of stringer-stiffened right-side wall. Co-nodes are used for the connection between the right-side wall and seven stringers. The stiffened left-side wall has the same structure as the right-side wall. Fig. 2c presents the FE model of bottom skin stiffened with ten stringers. The stringers have the same shape as those on the right-side wall. The bottom skin is also assembled with the stringers by using the co-node. An opening hole exists on the skin between frames T8 and T9, resulting in two middle interrupted stringers.

The top wall connects the left-side and right-side walls through the rib-band, while the bottom skin joints the side walls through the lug pieces at their locations shown in Fig. 3a. The connections are achieved by using the coupling element (DCOUP3D) and connecting element (CONN3D2). In order to simulate the rivet connection between the surrounding thin walls, the nodes of one element on the wall and another on the rib-band (or lug piece) are concentrated to two nodes by using DCOUP3D element first, the two concentrated nodes are then connected through CONN3D2 element, which is shown in Fig. 3b. The middle sidewall between frames T10 and T12 (Fig. 4a) and the end sidewall between frames T12 and T13 (Fig. 4b) are symmetrical about the longitudinal vertical middle plane of the beam. The central panels on middle and end sidewalls are honeycomb sandwich composites, which are ply changed to the laminated composites in the adjacent area. The T-shape attachment (Fig. 
4c) and tie constraint are used for connecting the middle sidewall. The end sidewall of the tail beam is connected with the inclined beam by using the upper and lower joints (Figs. 4d and 4e). The connections of the lug joints are achieved through the coupling element (DCOUP3D) shown in Fig. 4f.

Fig. 5 presents the FE models for frames T1 to T13. Frames T1 and T10 shown in Figs.5a and 5b are metal structures, whereas frames T2 to T9 are composite structures as shown in Fig. 5c. Frame T11 is an open metal structure consisting of five web plates with round flange (Fig. 5d). Frames T12 and T13 are metal structures enhanced with attachments as shown in Figs. 5e and 5f. Tie constraint is used for the connection between frames T2 to T9 and four surrounding thin walls, while the coupling and connecting elements (Fig. 3b) are used for the connection between frames T1, T10 to T13 and surrounding thin walls and for the connection between frame T1 and load transfer segment.

From the aforementioned FE modelling, it is evident that the tie constraint and co-node are used to model the skin/stiffener interface of tail structure. However, it is hard and formidable for the constraint and co-node to simulate and identify the delamination initiation and propagation on the skin/stiffener interface, likely causing a non-conservative prediction of fatigue life in progressive damage analysis. This drawback probably limits the effective use of proposed approach. Consequently, in order to obtain the more reasonable and valid predictions of helicopter tail structure, the practical technique is desired to model the skin/stiffener interface for progressive damage analysis of fatigue failure on the interface in the future work.

\section{VALIDATION OF FE MODELING}

Static tests were conducted on full-scale helicopter composite tail structure under two multipoint coordinated loading conditions representing left yawing and two-point horizontal landing during flight. By equivalently merging the actual load data, the multipoint loading locations and values under left yawing and two-point horizontal landing conditions were selected and determined (Fig. 6 and Table 5). The load transfer segment connected with tail beam was joined with the test rig by bolts. The tail structure was subjected to the multipoint loads as shown in Table 5 by $10 \%$ coordinated increment step by step under air moisture in the lab environment. Accordingly, for the FE modeling, the complete displacement constraint was applied to the end of load transfer segment (Fig. 7a). The multipoint loads under left yawing and two-point horizontal landing conditions in Table 5 were applied to the tail structure by using coupling elements (DCOUP3D) shown in Fig. 7b. The FE model 
of helicopter composite tail structure was then imported into the finite element software ABAQUS for stress analysis.

Fig. 8 shows four strain measuring sections S1 to S4 and four pair of symmetrical displacement measuring points. Fig. 9 and Table 6 present the locations and coordinates of the strain gauges on strain measuring sections S1 to S4. The simulation results are compared with the experimental results at the strain and displacement measuring points under $80 \%$ limit load of left yawing and $100 \%$ limit load of two-point horizontal landing conditions (Figs. 10 and 11). Fig. 10a illustrates the strain distributions on sections S1 to S4 under left yawing condition. It can be seen from Fig. 10a that the strain on sections S1 to S4 reaches the maximum value at strain gauge 7 and the minimum value at strain gauge 3, which is related to the applied loads mainly composed of the positive loads in Y-axis direction and negative loads in Z-axis direction. Fig. 10b indicates the displacement results at four pair of displacement measuring points under left yawing condition. The helicopter composite tail structure bends down to the left under the main positive Y-axial loads and negative Z-axial loads. Thus, the Y-axial displacement is positive while the Z-axial displacement is negative, which increase with the measuring points moving to the end of tail structure. Fig. 11a illustrates the strain distribution on sections S1 to S4 under two-point horizontal landing condition, showing that the strain on sections $\mathrm{S} 1$ to $\mathrm{S} 4$ reaches the maximum value at strain gauge 1 or 8 and the minimum value at one of strain gauges 3 to 6 . The upper part is in tension while the lower part is in compression under the bending moment caused by the negative Z-axial loads without Y-axial loads. Note that sections S3 and S4 are close to the load transfer segment which has inverted U-shaped boundary rather than a closed boundary condition, leading to limited load transferred to the locations of strain gauges 4 and 5 . As a result, the strain distribution on sections S3 and S4 is similar to a W-shaped line. Fig. 11b illustrates the displacement results at four pair of displacement measuring points under two-point horizontal landing condition. The Y-axial displacement is close to zero, while the Z-axial displacement is negative which increases with the measuring points moving to the end of tail structure.

It can be seen from Figs. 10 and 11 that both the simulated strain and displacement results agree well with the experimental results, validating the FE model of helicopter composite tail structure. There is small deviation between the strain results of simulation and experiments, which could be attributed to the deviation in the installation of test piece and strain gauges. In addition, the fact that the simulated displacement results are lower than experimental results could be rationalized by the higher 
stiffness of FE model with idealization of material. Another reason for the lower simulated displacement is that the complete displacement constraint is used as the boundary condition in FE model which does not account for the deformation of bolt connection in test.

\section{PROGRESSIVE DAMAGE ANALYSIS}

The progressive damage analysis has been proven to be an effective method in predicting the fatigue life and failure process of composite structure ${ }^{[27]}$. Fig. 12 presents the flowchart of progressive damage analysis under fatigue spectrum loading. Through iterative cycles of FE stress analysis, failure identification and material property degradation until final structure failure, the fatigue life and damage propagation of composite structure can be predicted under spectrum loading.

Fatigue residual strength model for characterizing material property degradation of element is

$$
n=\frac{\left[R_{0}-R(n)\right]^{\nu}}{C\left(S-S_{0}\right)^{\mu}}
$$

where $n$ is the number of fatigue loading cycles; $S$ is the maximum absolute value of fatigue stress; $R(n)$ is the residual strength after $n$ number of cycles; $S_{0}$ is the fatigue endurance limit of composites; $R_{0}$ is the initial strength of composites; $C, \mu$ and $v$ are model parameters.

The residual strength model at $n+\Delta n$ loading cycles is

$$
n+\Delta n=\frac{\left[R_{0}-R(n+\Delta n)\right]^{\nu}}{C\left(S-S_{0}\right)^{\mu}}
$$

Taking transformation of Eqs. (1) and (2), the strength degradation of composite material under $\Delta n$ cycles of stress $S$ is obtained as

$$
R(n+\Delta n)=R_{0}-\left\{C\left(S-S_{0}\right)^{\mu} \Delta n+\left[R_{0}-R(n)\right]^{\nu}\right\}^{\frac{1}{v}}
$$

Eq. (3) is the governing equation of strength degradation model at a given stress ratio of $r_{0}$. It has been recognized that fatigue tests are usually conducted only at a specific stress ratio of $r_{0}$ to determine fatigue residual strength property of composites. Conversely, many composite structures always undergo variable-amplitude rather than constant-amplitude loading history. Consequently, the effect of stress ratio needs to be considered in the characterization model for fatigue residual strength property of composites, namely, it is essential to correct fatigue residual strength property of composites in order to be suited for the stress cycles with different stress ratios in an actual random 
spectrum load history using the empirical constant life diagram (e.g. Goodman, Smith or Soderberg, Bagci and Gerber diagrams, etc.). Empirical Goodman diagram is valid for the brittle materials and is conservative for the ductile materials as follows.

$$
\frac{S_{a}}{S_{-1}}+\frac{S_{m}}{\sigma_{b}}=1
$$

where $S_{a}$ and $S_{m}$ are the stress amplitude and mean stress of the fatigue cycle. $\sigma_{b}$ is the ultimate strength of the material which is either the ultimate tensile strength during the tension-dominated stress ratio range of $[-1,1]$ or the ultimate compressive strength during the compression-dominated stress ratio range of $(-\infty,-1) \cup 、$. The initial strength of composites equals the absolute value of ultimate strength $R_{0}=\left|\sigma_{b}\right| . S_{-1}$ is the fatigue strength depicted with stress amplitude under fully reversed cyclic loading. Note that fatigue stress level (i.e., $S_{a}$ and $S_{m}$ ) governs fatigue life of material, that is, if fatigue stress levels are different, then the relevant fatigue lives of material are different, and thus the Goodman constant life diagrams pertaining to different fatigue lives are different and the values of $S_{-1}$ on the Goodman diagrams are then different. In general, $S_{-1}$ on the Goodman diagrams during medium and long life regimes is defined as the fatigue strength depicted with stress amplitude under fully reversed cyclic loading, however, $S_{-1}$ during long life regime is also termed as the fatigue endurance limit. In short, fatigue strength $S_{-1}$ depends on fatigue stress level (i.e., $S_{a}$ and $S_{m}$ ) and the relationship between fatigue strength $S_{-1}$ and fatigue stress level (i.e., $S_{a}$ and $S_{m}$ ) is depicted by the Goodman constant life diagram or Equation (4).

From the definition of stress ratio, taking the transformation of Eq. (4) gives ${ }^{[27]}$

$$
\left\{\begin{array}{cl}
S_{r_{0}}=\frac{2 R_{0}(1-r)}{\left(1-r_{0}\right)\left[2 R_{0}-(1+r) S_{r}\right]+\left(1+r_{0}\right)(1-r) S_{r}} S_{r}, & -1 \leq r \leq 1 \\
S_{r_{0}}=\frac{-2 r_{0} R_{0}(1-r)}{\left(1-r_{0}\right)\left[-2 r R_{0}+(1+r) S_{r}\right]-\left(1+r_{0}\right)(1-r) S_{r}} S_{r}, & r<-1 \text { or } r>1 \\
r_{0}<-1 \text { or } r_{0}>1
\end{array}\right.
$$

Substituting Eq. (5) into Eq. (3) gives the strength degradation model for arbitrary stress ratio of $r$. 


$$
\left\{\begin{array}{c}
R(n+\Delta n)=R_{0}-\left\{C\left\{\frac{2 R_{0}(1-r) S_{r}}{\left(1-r_{0}\right)\left[2 R_{0}-(1+r) S_{r}\right]+\left(1+r_{0}\right)(1-r) S_{r}}-S_{0}\right\}^{\mu} \Delta n+\left[R_{0}-R(n)\right]^{\nu}\right\}^{\frac{1}{v}} \quad \begin{array}{l}
-1 \leq r \leq 1, \\
-1 \leq r_{0} \leq 1
\end{array} \\
R(n+\Delta n)=R_{0}-\left\{C\left\{\frac{-2 r_{0} R_{0}(1-r) S_{r}}{\left(1-r_{0}\right)\left[-2 r R_{0}+(1+r) S_{r}\right]-\left(1+r_{0}\right)(1-r) S_{r}}-S_{0}\right\}^{\mu} \Delta n+\left[R_{0}-R(n)\right]^{v}\right\}^{\frac{1}{v}} \quad \begin{array}{l}
r<-1 \text { or } r>1, \\
r_{0}<-1 \text { or } r_{0}>1
\end{array}
\end{array}\right.
$$

After fatigue load is applied on the FE model according to the load spectrum, the stress state of elements is calculated by using non-linear FE method. The residual strength of element material is gradually degraded by using Eq. (6). The failure of element is identified by residual strength criterion. Namely, when the residual strength equals the fatigue stress, the failure of element is identified.

$$
R(n) \leq S
$$

If failure happens, the stiffness of failed elements is degraded to nearly zero and then the FE stress analysis is re-executed. The above material property degradation rules and element failure identification are realized by the user subroutine. It is worth noting that the ratio between tensile strength and compressive strength is used to adjust the residual strength of the material when the transition between tensile and compressive fatigue loading cycles occurs.

By using fatigue progressive damage algorithm in Fig. 12, fatigue life and damage propagation were evaluated based on the established FE model of helicopter composite tail structure (Figs. 1) under multipoint coordinated spectrum loading. The loading positions and spectrum load histories are shown in Figs. 6 and 13, respectively. The load spectrum is equivalent to fatigue loads undertaken by the helicopter tail structure during 1000 flight hours.

During the spectrum fatigue test, no damage was detected on the helicopter tail structure after 48 repeated applications of load spectrum by using nondestructive inspection techniques. An impact damage was subsequently introduced on the left-side wall between frames T7 and T8 to simulate the impact damage which might occur on tail structure during service (Fig. 14). The impact was performed using pendulum impact testing machine with $16 \mathrm{~mm}$ diameter impact object and a baffle plate to prevent secondary impact. Figs. $15 \mathrm{a}$ and $15 \mathrm{~b}$ present the macro photograph and C-Scan results of impact damage on the post-impact left-side wall. The impact damage size is measured to be 33 $\mathrm{mm} \times 21 \mathrm{~mm}$ using C-Scan techniques. The multipoint coordinated spectrum fatigue test was then continued on the post-impact helicopter composite tail structure. After another 8 repeated applications of the load spectrum, the C-Scan results showed that the impact damage area expanded to $37.5 \mathrm{~mm} \times 23 \mathrm{~mm}$ (Fig. $15 \mathrm{c})$. 
As the impact damage was introduced to the laminated composite part of the tail structure, the progressive damage analysis is carried out only for the laminated composite part. The metal and composite honeycomb sandwich structures are considered as the effective load transfer structures without damage due to their high mechanical performance. The strength degradation models developed in literature [27] is implemented as the material property degradation metric. Eq. (8) is the strength degradation model used for material property degradation of laminated composite part of the tail structure.

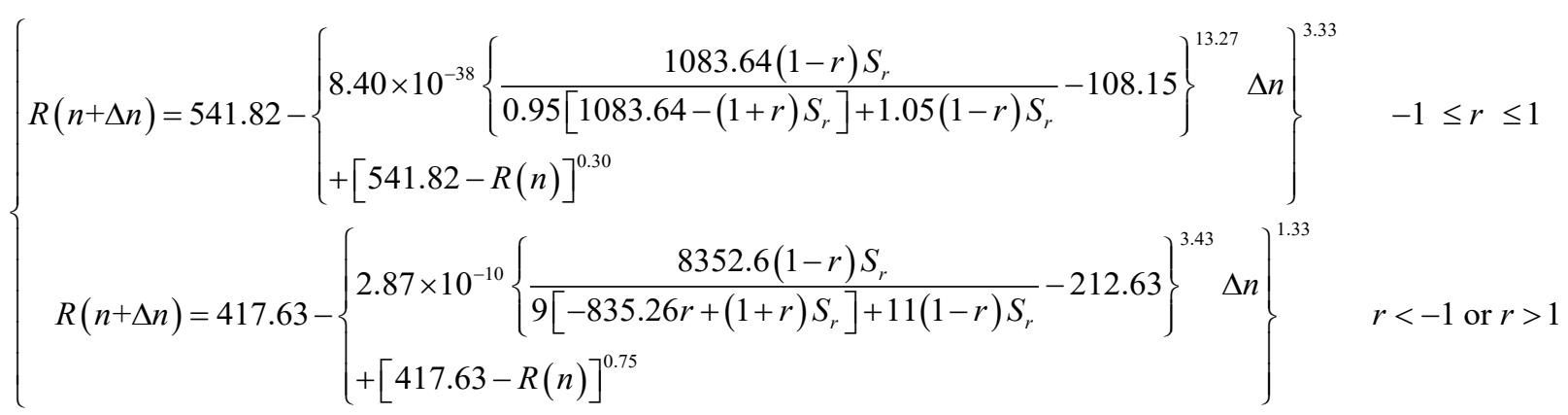

Fig. 16 presents the damage propagation on the full-scale composite tail structure of helicopter under multipoint coordinated spectrum loading. It is shown in Fig. 16a that no failed element appears after 48 repeated applications of the load spectrum, which is consistent with the experimental finding. The mesh at the impact damage position of fatigued model is then modified to reflect the C-Scan result after impact test. That is, an open hole of $33 \mathrm{~mm} \times 21 \mathrm{~mm}$ on the left-side wall between frames $\mathrm{T} 7$ and T8 is employed to simulate the impact damage. After that the progressive damage analysis is continued on the post-impact tail structure under multipoint coordinated spectrum loading. Fig. 16b presents the damage state of post-impact tail structure after a further 6 repeated applications of the load spectrum in the second stage, showing that some failed elements appear around the impact position and on the top wall near frame T10. The propagation of impact damage on tail structure model after $48+6$ repeated applications of the load spectrum is consistent with the experimental results. Fig. 16c presents the further damage state of post-impact tail structure after 16 repeated applications of the load spectrum in the second stage. It is found that the damage on top wall near frame T10 propagates to a critical size, leading to the final fracture of the helicopter tail structure. The damage area around the impact position however only expands limitedly.

The aforementioned progressive damage analysis has been proven to be a practical engineering tool for fatigue life prediction of helicopter composite tail structure because of the good agreement between life predictions and experiments. Both the results of FE simulation and fatigue test show no 
fatigue damage after 48 repeated applications of the load spectrum, which is equivalent to 48,000 flight hours. The impact damage of $33 \mathrm{~mm} \times 21 \mathrm{~mm}$ on tail structure model propagates after another 6 repeated applications of the flight spectrum loading, which agrees well with experimental results. The residual life prediction of helicopter composite tail structure after the introduction of impact damage is further 16 repeated applications (16000 flight hours) of the load spectrum. These results demonstrate that the developed progressive damage algorithm can effectively predict fatigue damage propagation in composite structures and has the great potential for application in tolerance design of aircraft composite structures. It is also worth noting that the impact damage on tail structure model propagates only with a small amount. The damage near frame T10 however expands to a critical area, causing the final fracture of helicopter tail structure. In reality, the composite laminated walls and honeycomb sandwich middle sidewalls are connected with metal structure of frame T10. The material discontinuity around frame T10 induces even more severe stress concentration than that around the impact damage on the left-side wall between frames T7 and T8. It indicates that progressive fatigue damage analysis can reasonably predict damage inspection locations for maintenance of aircraft composite structures, avoiding the potential omission of early damage which might lead to structure failure.

Notably, the predictions of residual life and fracture location for helicopter composite tail structure after the introduction of impact damage necessitate further experimental verification. That is, experiments should be extended to a longer range of fatigue life until final fracture for the helicopter tail structure to validate the finding of numerical modelling. However, we were constrained by what could be achieved in the context of work that was predefined for us by the sponsors. This forms the basis for some further investigation.

\section{CONCLUSIONS}

This paper presents a numerical study on fatigue life prediction of helicopter composite tail structure under multipoint coordinated loading spectrum. Following conclusions can be drawn from the investigation.

(i) A FE model has been developed for the helicopter composite tail structure. The simulated strain and displacement results agree well with the experimental results under left yawing and two-point horizontal landing conditions, demonstrating the validity of the FE model of helicopter composite tail structure. 
(ii) No failed element appears on helicopter composite tail structure after 48 repeated applications of the load spectrum, which is consistent with fatigue test observation. The impact damage introduced on the left-side wall between frames T7 and T8 propagates after another 6 repeated applications of the load spectrum, showing a good correlation with experimental results. The results demonstrate that the progressive damage analysis has reasonable accuracy.

(iii) The residual life prediction of helicopter composite tail structure under multipoint coordinated spectrum loading after the introduction of impact damage is 16 repeated applications (16000 flight hours) of the load spectrum, demonstrating that the progressive damage analysis is a practical tool for fatigue life prediction of aircraft composite structures.

\section{ACKNOWLEDGEMENT}

This project was supported by the National Natural Science Foundation of China (Grant No. $51875021)$.

\section{REFERENCES}

[1] Xiong JJ, Shenoi RA. General aspects on structural integrity. Chinese J Aeronaut, 2019; 32(1): 114-132.

[2] Cvitkovich MK, Brien TK, Minguet PJ. Fatigue debonding characterization in composite skin/stringer configurations, NASA Technical Memorandum 110331. USA: Virginia; 1997.

[3] Thawre MM, Pandey KN, Dubey A, Verma KK, Peshwe DR, Paretkar RK, Jagannathan N, Manjunatha CM. Fatigue life of a carbon fiber composite T-joint under a standard fighter aircraft spectrum load sequence. Compos Struct, 2015; 127: 260-266.

[4] Zhang YD, Zhang L, Guo LC, Feng YB, Liu G, Sun XY. Investigation on fatigue performance of T800 composites structural component. Compos Struct, 2018; 195: 26-35.

[5] Chen X. Experimental observation of fatigue degradation in a composite wind turbine blade. Compos Struct, 2019; 212: 547-551.

[6] Huang X, Zhao S. Damage tolerance characterization of carbon fiber composites at a component level: A thermoset carbon fiber composite. J Compos Mater, 2018; 52: 37-46.

[7] Aoki Y, Ishikawa T, Takeda S, Hayakawa Y, Harada A, Kikukawa H. Fatigue test of lightweight composite wing structure. Int J Fatigue, 2006; 28(10): 1109-1115.

[8] Tan Y, Wu G, Suh SS, Yang JM, Hahn HT. Damage tolerance and durability of selectively stitched stiffened composite structures. Int J Fatigue, 2008; 30: 483-492. 
[9] Bisagni C, Furfari D, Pacchione M. Fatigue and Damage Tolerance Assessment of 3-D reinforced CFRP Bonded Joints, 28th ICAF Symposium, Helsinki, 3-5 June 2015.

[10] Liu Y, Zhang X, Lemanski SL, Nezhad HY, Ayre D. Experimental and numerical study of process-induced defects and their effect on fatigue debonding in composite joints. Int J Fatigue, 2019; 125: 47-57.

[11] Bisagni C, Davila CG. Experimental investigation of the postbuckling response and collapse of a single-stringer specimen. Compos Struct, 2014; 108: 493-503.

[12] Davila CG, Bisagni C. Fatigue life and damage tolerance of postbuckled composite stiffened structures with initial delamination. Compos Struct, 2017; 161: 73-84.

[13] Akker BPH, Donadon MV, Loendersloot R, Oliveira LA, Arbelo MA. The influence of hygrothermal aging on the fatigue behavior and residual strength of post-buckled co-bonded stiffened panels subjected to compressive loading. Compos Part B: Eng, 2020; 194: 108023.

[14] Attia O, Kinloch AJ, Matthews FL. Modelling the fatigue life of polymer-matrix fibre-composite components. Compos Sci Technol, 2001; 61(15): 2273-2283.

[15] Attia O, Kinloch AJ, Matthews FL. The prediction of fatigue damage growth in impact-damaged composite skin/stringer structures. Part I: theoretical modelling studies. Compos Sci Technol, 2003; 63(10): 1463-1472.

[16] Raimondo A, Bisagni C. Fatigue analysis of a post-buckled composite single-stringer specimen taking into account the local stress ratio. Compos Part B: Eng, 2020; 193: 108000.

[17] Shokrieh MM, Lessard LB. Progressive fatigue damage modeling of composite materials, Part I: Modeling. J Compos Mater, 2000; 34: 1056-1080.

[18] Shokrieh MM, Lessard LB. Progressive fatigue damage modeling of composite materials, part II: material characterization and model verification. J Compos Mater, 2000; 34: 1081-1116.

[19] Lian W, Yao WX. Fatigue life prediction of composite laminates by FEA simulation method. Int J Fatigue, 2010; 32(1): 123-133.

[20] Eliopoulos EN, Philippidis TP. A progressive damage simulation algorithm for GFRP composites under cyclic loading. Part II: FE implementation and model validation. Compos Sci Technol, 2011; 71: $750-757$.

[21] Mohammadi B, Fazlali B, Salimi-Majd D. Development of a continuum damage model for fatigue life prediction of laminated composites. Compos Part A: Appl Sci Manufac, 2017; 93: 163 - 
176.

[22] Koch I, Zscheyge M, Tittmann K, Gude M. Numerical fatigue analysis of CFRP components. Compos Struct, 2017; 168: 392-401.

[23] Rivera JA, Aguilar E, Cárdenas D, Elizalde H, Probst O. Progressive failure analysis for thinwalled composite beams under fatigue loads. Compos Struct, 2016; 154: 79-91.

[24] Caous D, Bois C, Wahl J, Palin T, Valette J. Toward composite wind turbine blade fatigue life assessment using ply scale damage model. Procedia Eng, 2018; 213: 173-182.

[25] Rayavarapu VK. Damage tolerance evaluation of rotorcraft horizontal tail under variable amplitude service loading conditions. J Fail Anal and Preven, 2018; 18(3): 690-698.

[26] Rice RC, Jackson JL, Bakuckas J, Thompson S. Metallic materials properties development and standardization. Met Mater Prop Dev Stand Rep No MMPDS-01 DOT/FAA 2003.

[27] Wan AS, Xu YG, Xiong JJ. Notch effect on strength and fatigue life of woven composite laminates. Int J Fatigue, 2019; 127: 275-290.

[28] Zhang YB, Fu HM, Wang ZH, Ma XB. Open hole fatigue characteristic and probabilistic model for fatigue life prediction of CCF300/QY8911 and T300/QY8911 composite laminates. J Compos Mater, 2015; 49: 3205-3214.

[29] Farshidi A, Berggreen C, Schäuble R. Numerical fracture analysis and model validation for disbonded honeycomb core sandwich composites. Compos Struct, 2019; 210: 231-238. 


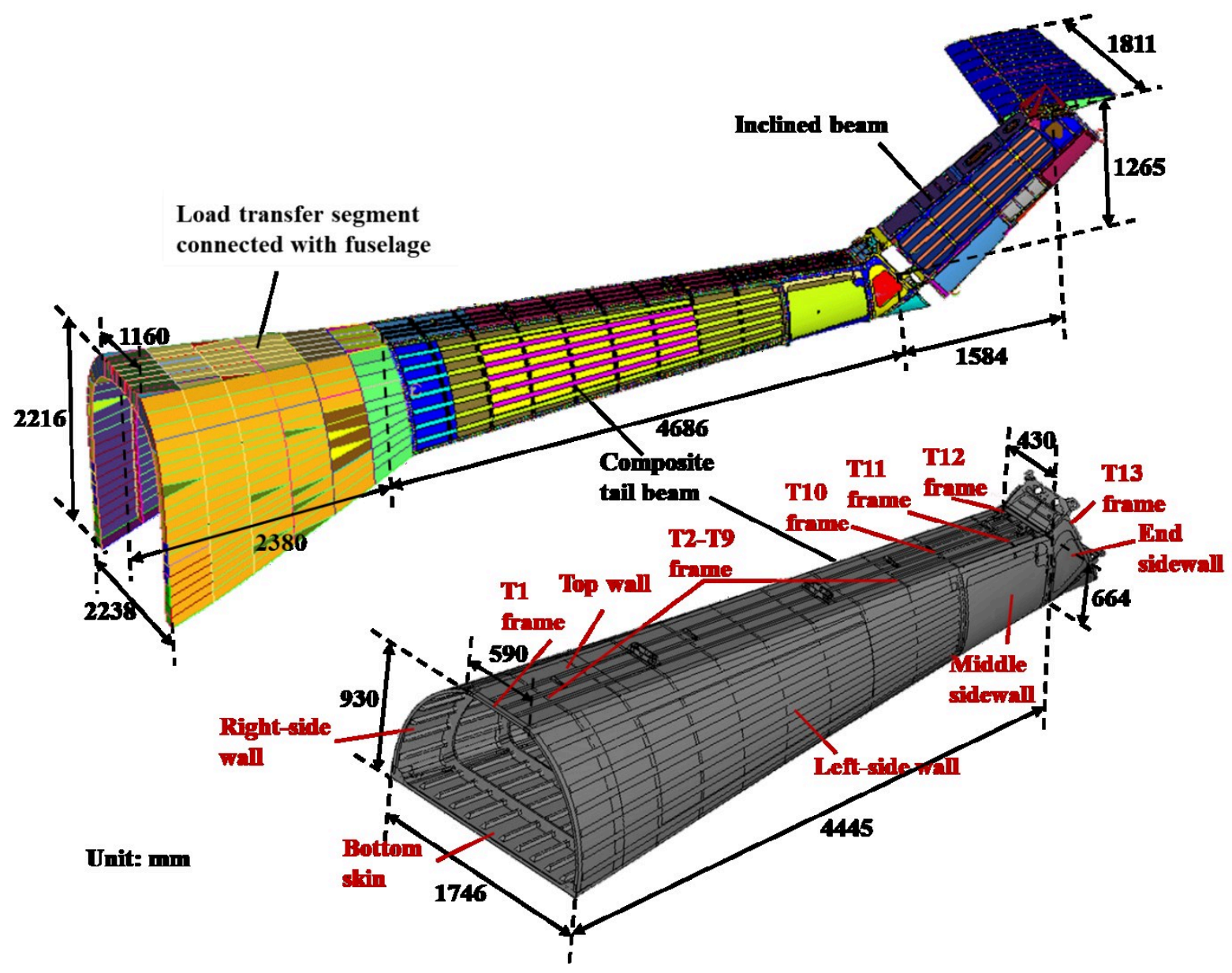

Fig. 1 Geometry and dimensions of helicopter composite tail structure.

(a)

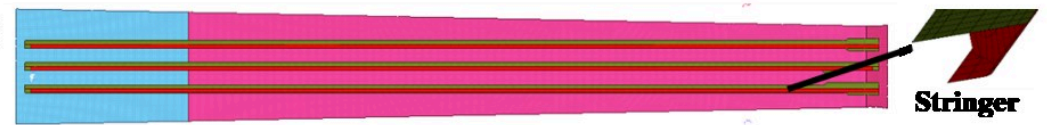

(b)

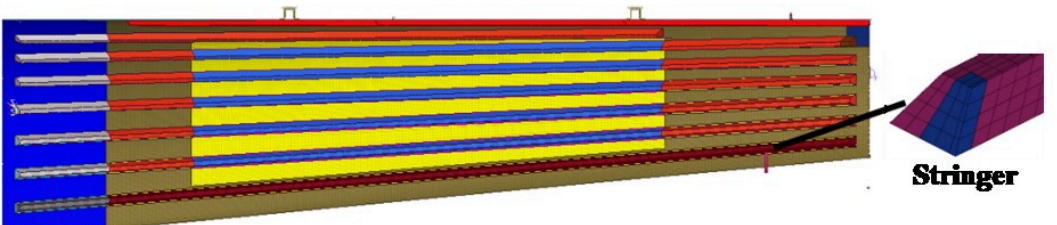

(c)

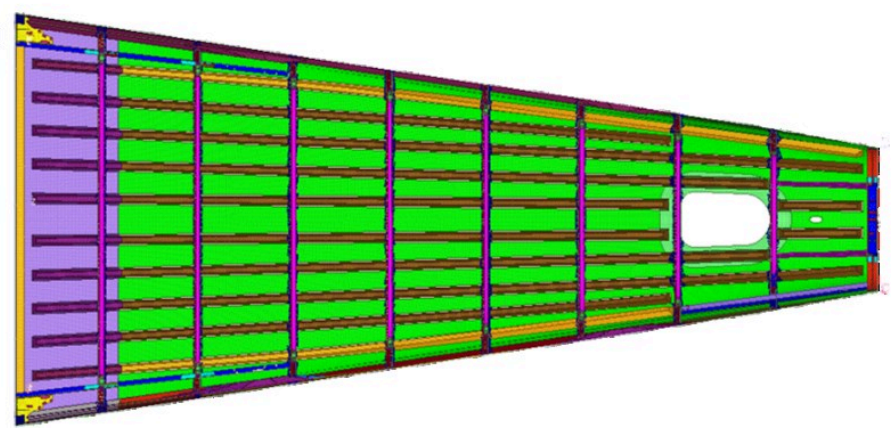

Fig. 2 FE models of surrounding stiffened thin-wall structures of helicopter tail structure: (a) top stiffened wall, (b) right-side stiffened wall, (c) bottom stiffened skin. 
(a)

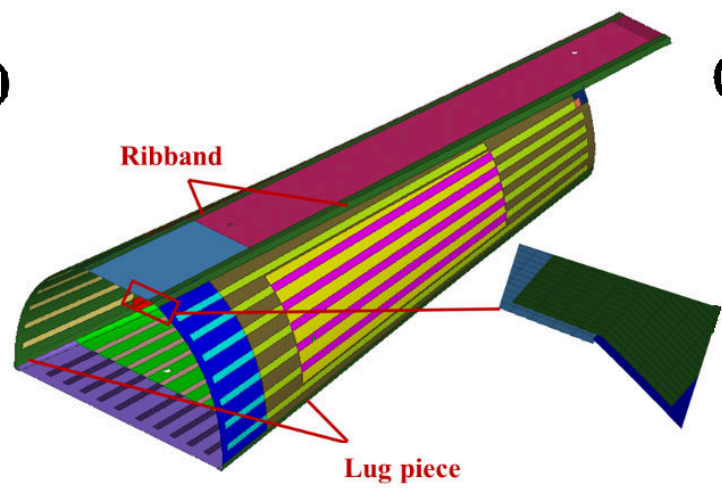

(b)



Fig. 3 Connections between surrounding thin walls in helicopter tail structure: (a) connections between four surrounding thin walls, (b) connections by coupling and connecting elements.

(a)

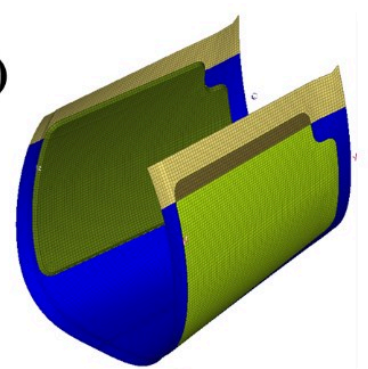

(d)

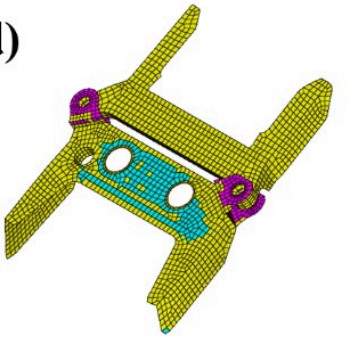

(b)



(e)

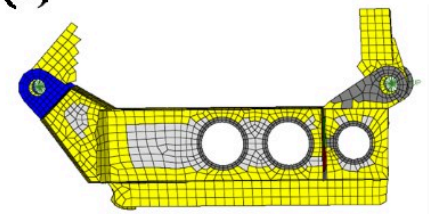

(c)

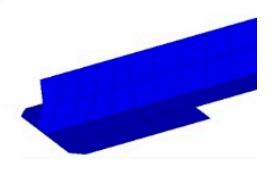

(f)

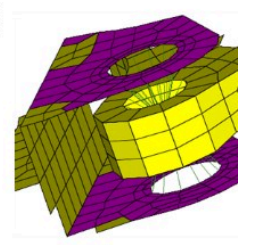

Fig. 4 Middle and end sidewall structures and connections: (a) middle sidewall, (b) end sidewall,

(c) T-shape attachment, (d) upper joint between end sidewall and inclined beam, (e) lower joint between end sidewall and inclined beam, (f) connection by coupling element. 
(a)

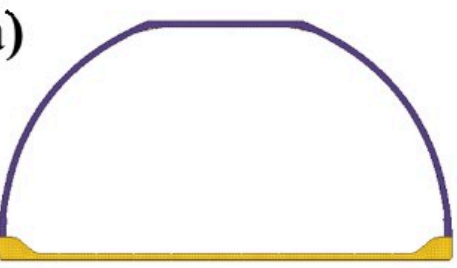

(d)

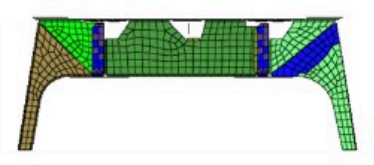

(b)

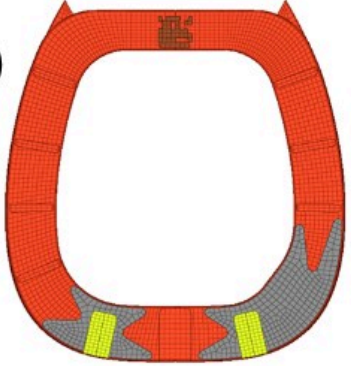

(e)

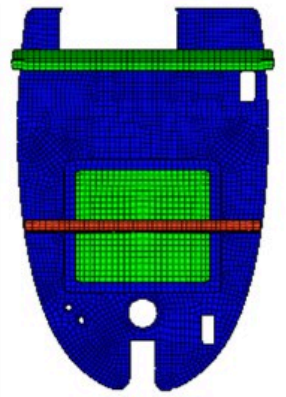

(c)

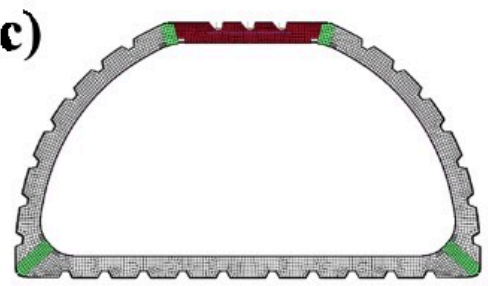

(f)

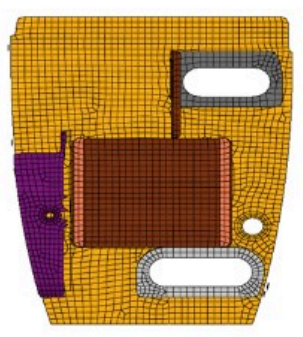

Fig. 5 FE models of frame structures of the tail structure: (a) frame T1, (b) frame T10, (c) frames T2 to T9, (d) frame T11, (e) frame T12, (f) frame T13.

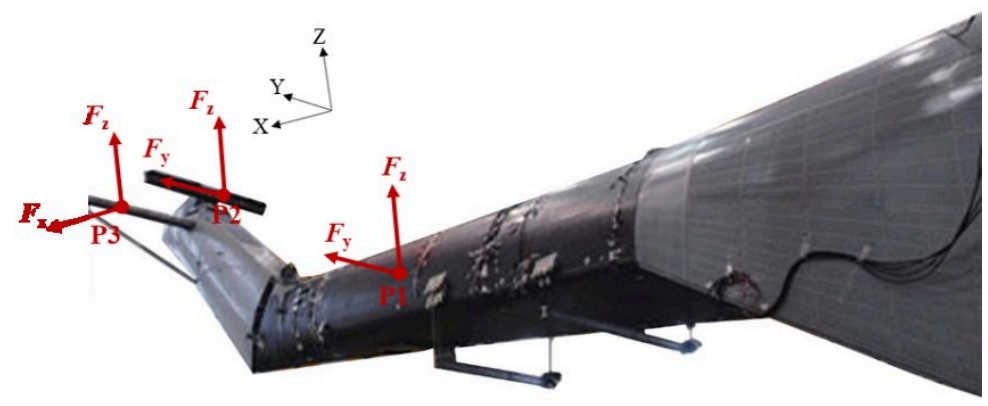

Fig. 6 Multipoint loads on full-scale composite tail structure of helicopter.

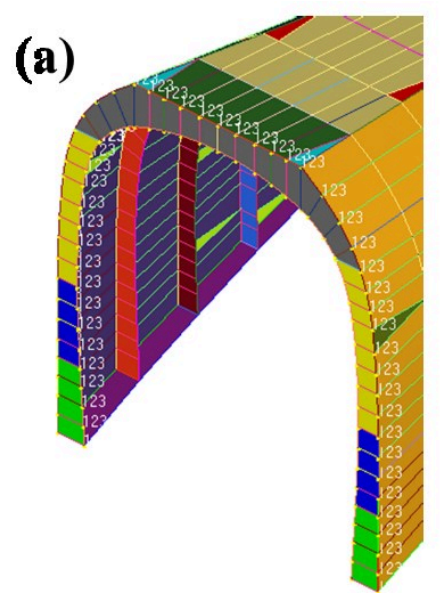

(b)

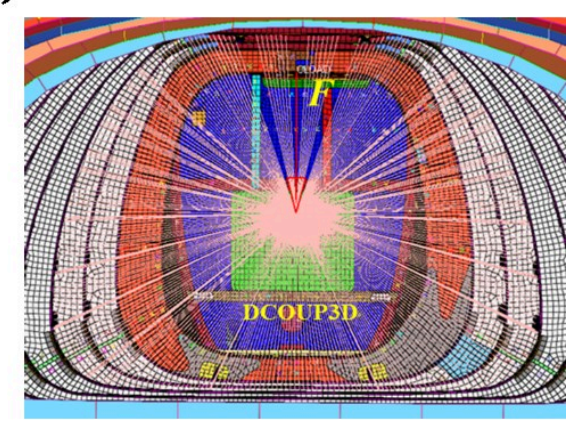

Fig. 7 Load and boundary conditions: (a) complete displacement constraint, (b) load application. 


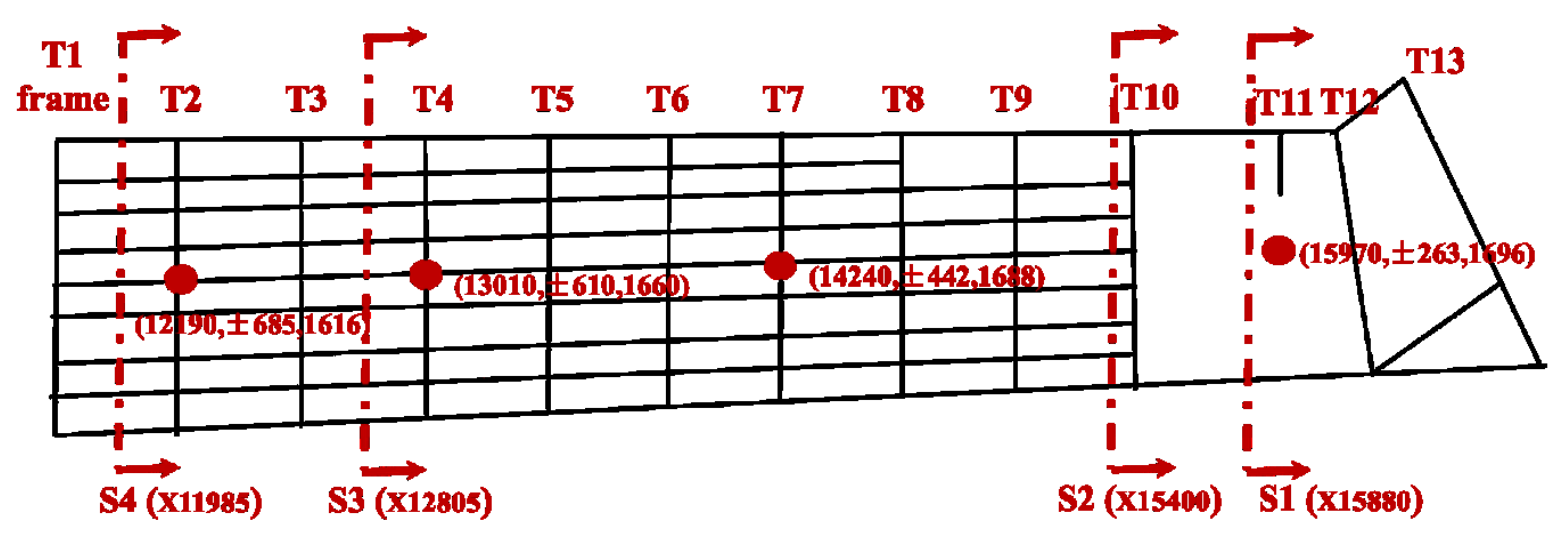

Displacement measuring point

Fig. 8 Strain measuring sections and displacement measuring points (unit: $\mathrm{mm}$ ).



Fig. 9 Strain gauges on strain measuring section.

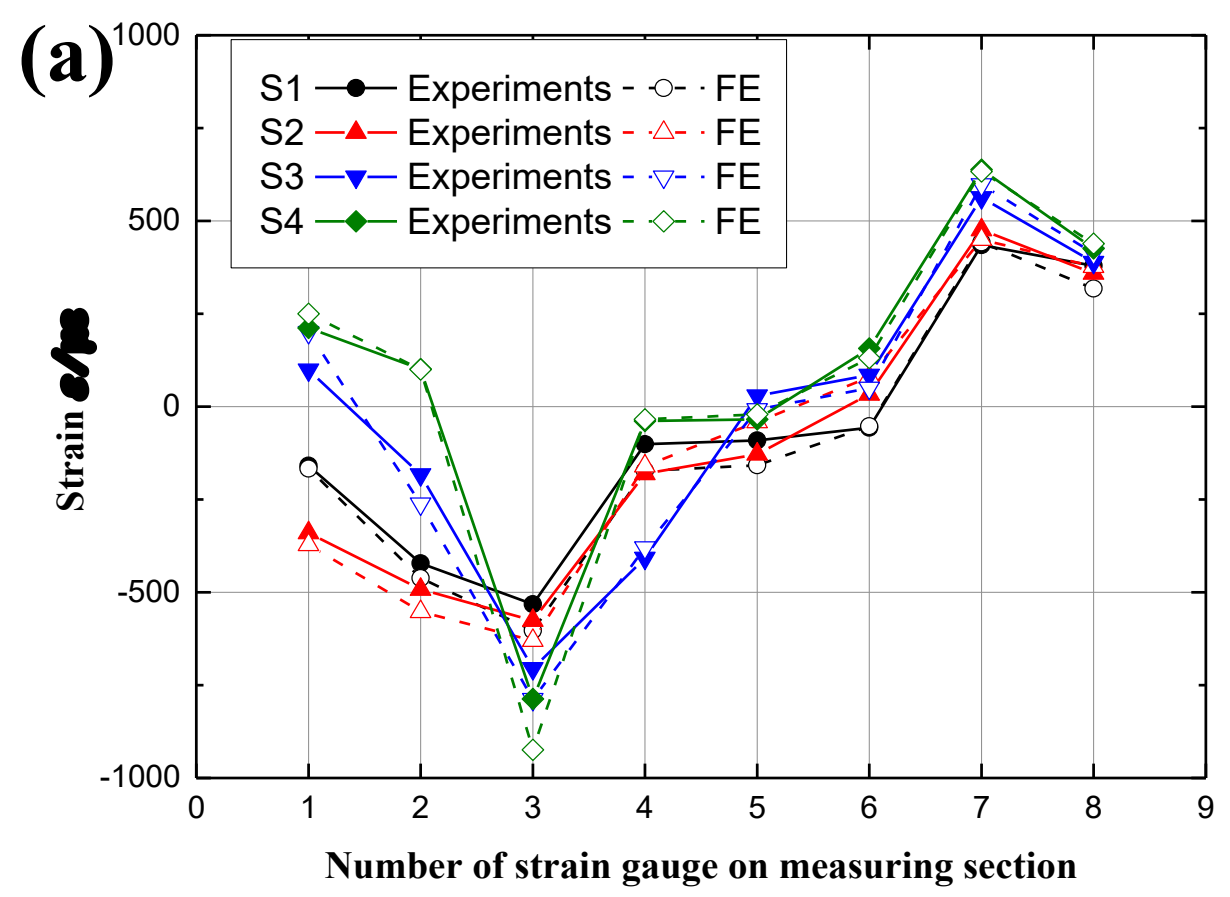




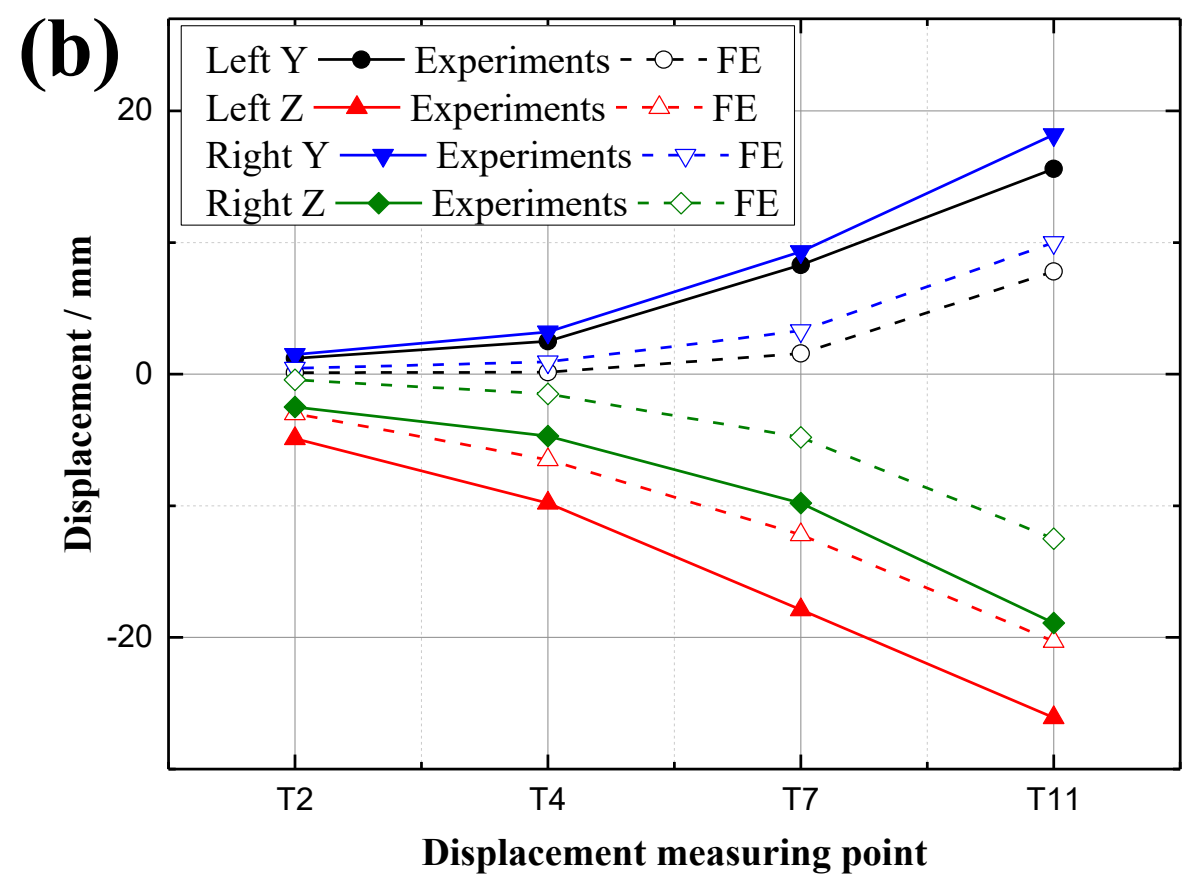

Fig. 10 Strain and displacement results under left yawing condition: (a) strain results, (b) displacement results.






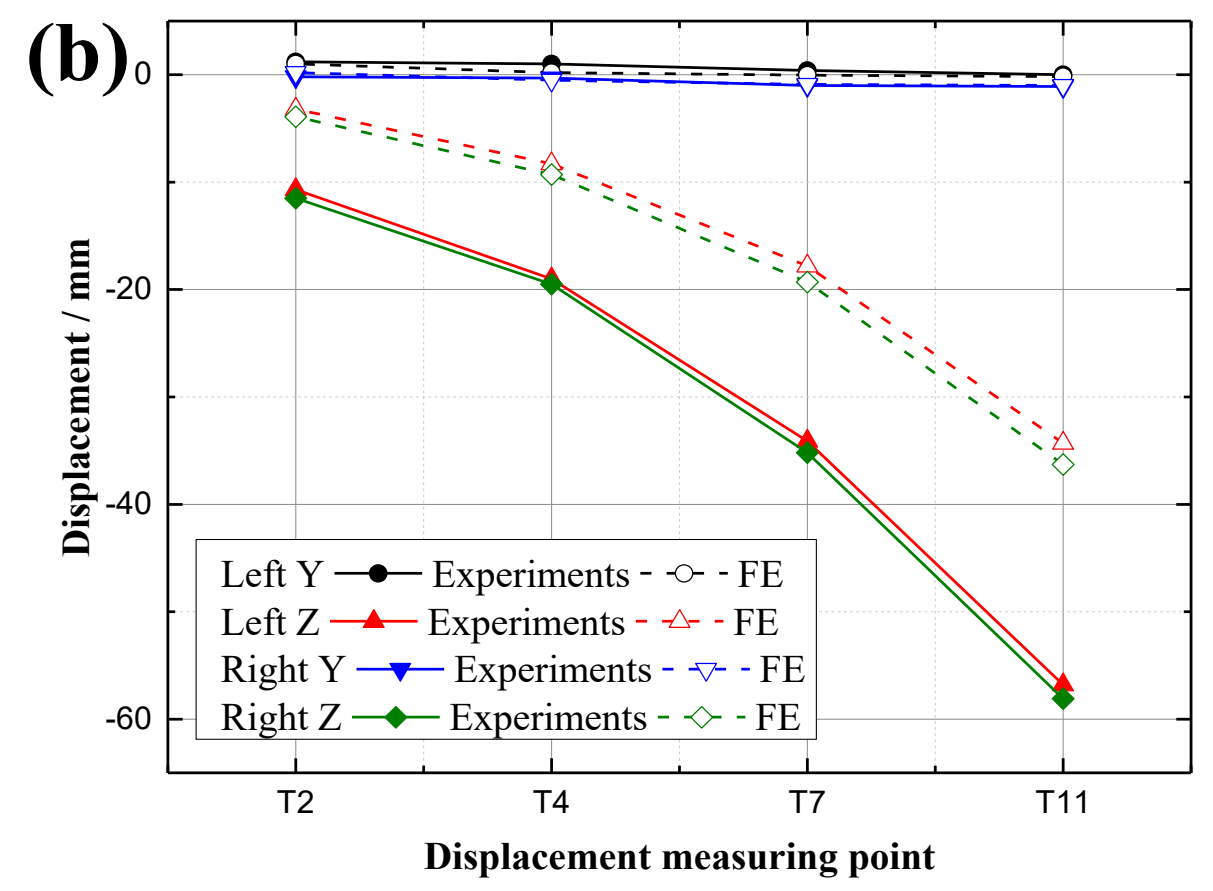

Fig. 11 Strain and displacement results under two-point horizontal landing condition: (a) strain results, (b) displacement results.

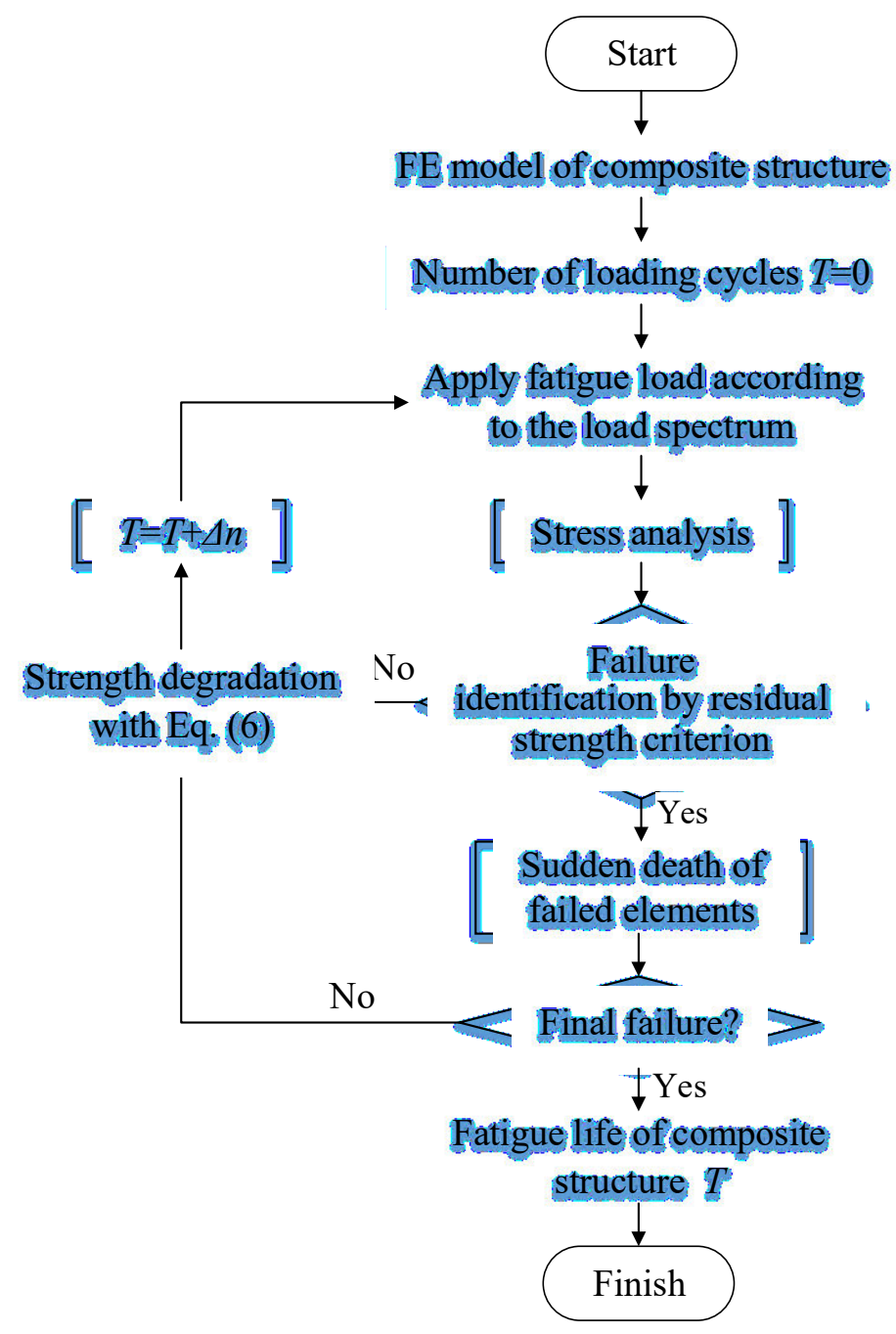


Fig. 12 Flowchart of progressive damage analysis under fatigue spectrum loading.
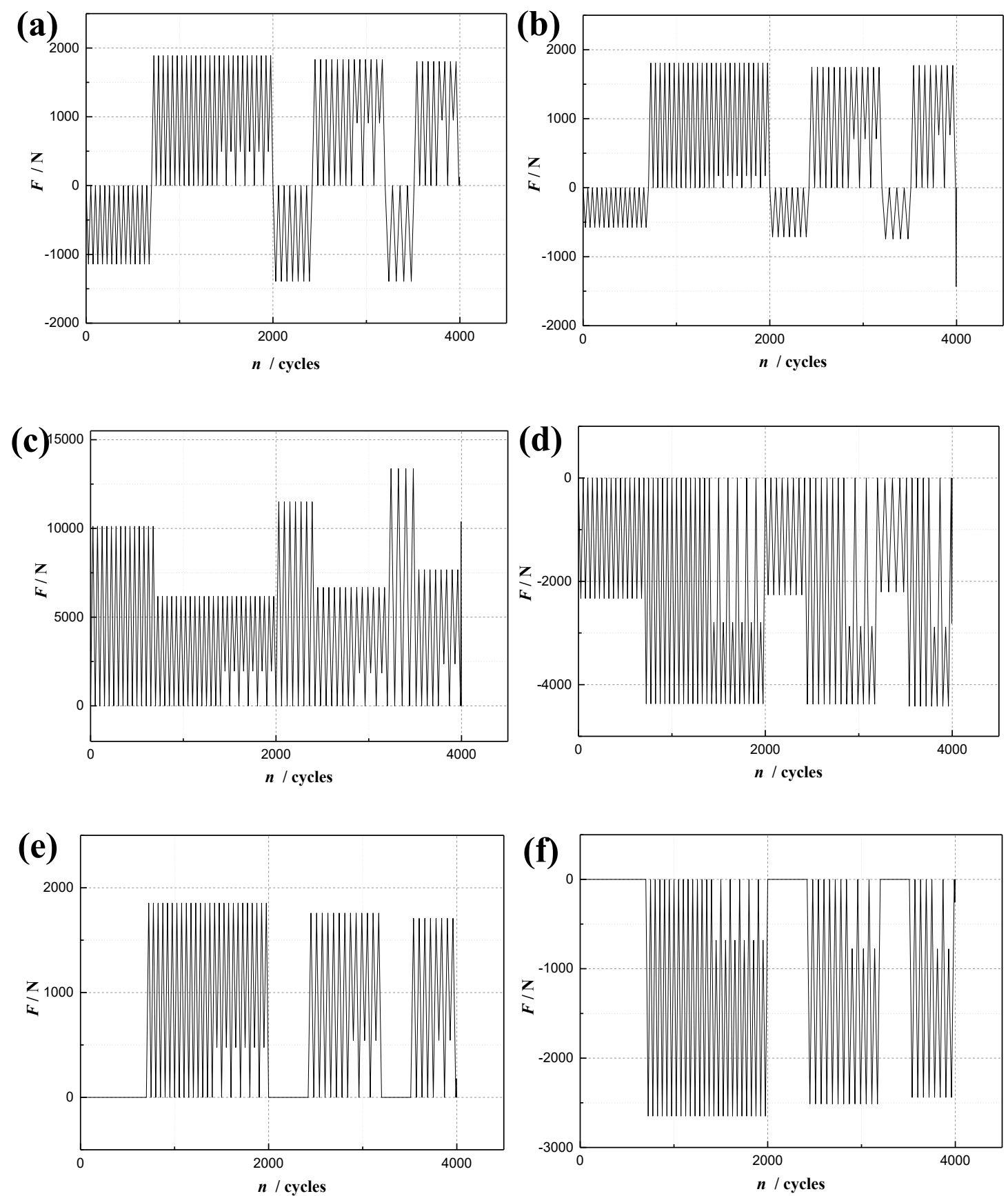

Fig. 13 Load histories on multiple points of tail structure: (a) P1 in Y direction, (b) P1 in Z direction, (c) P2 in $\mathrm{Y}$ direction, (d) P2 in $\mathrm{Z}$ direction, (e) P3 in $\mathrm{X}$ direction, (f) P3 in Z direction 


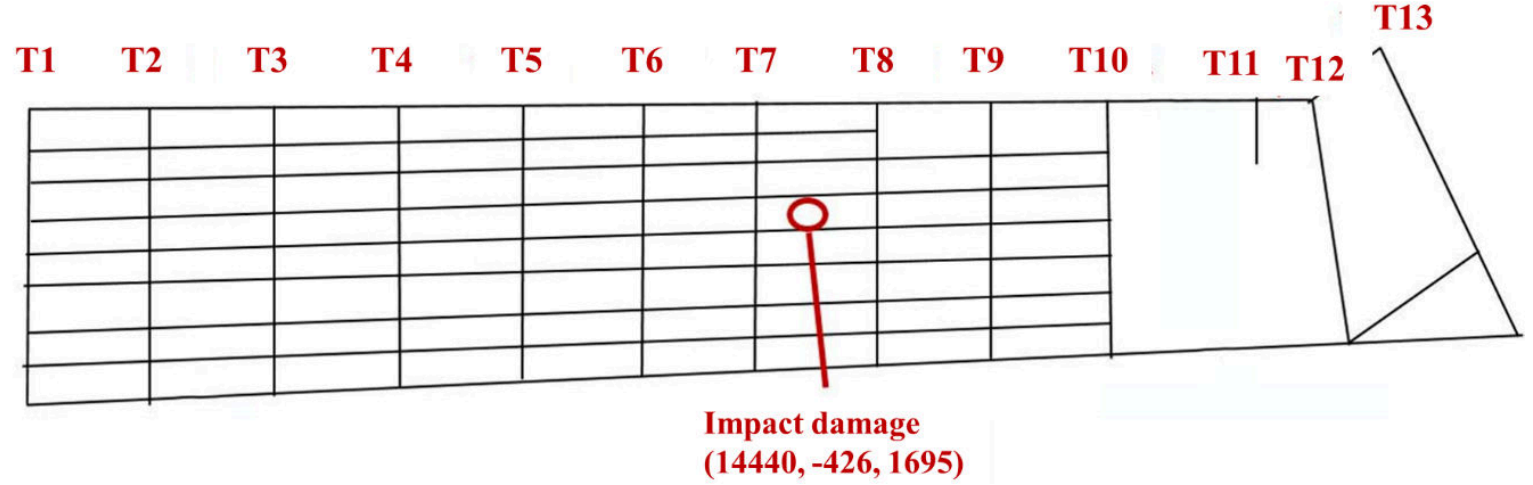

Fig. 14 Impact position on composite tail structure (unit: $\mathrm{mm}$ ).

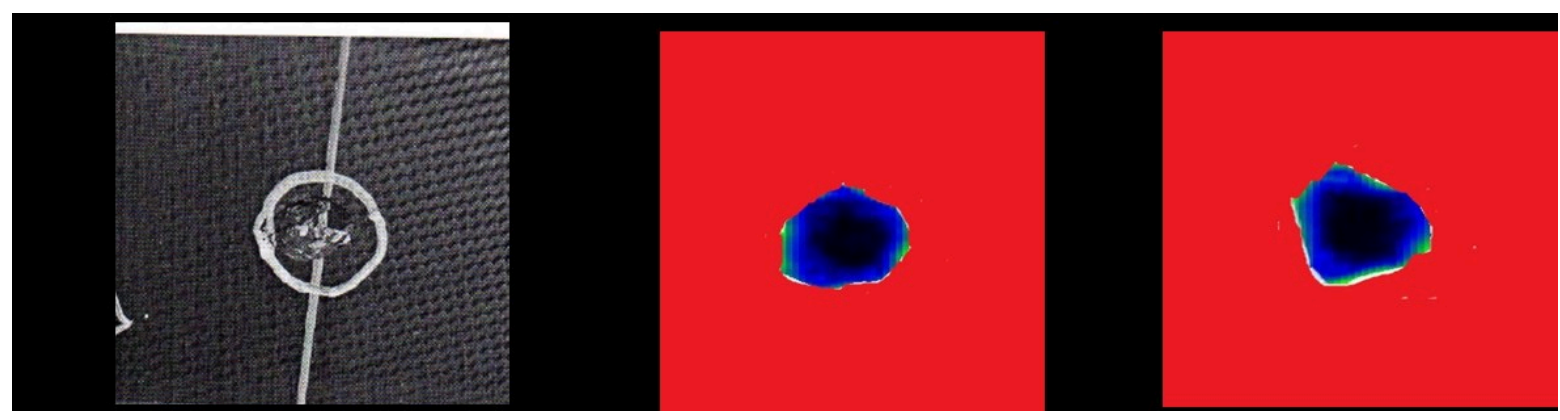

Fig. 15 Impact damage on composite tail structure: (a) macro photograph, (b) C-Scan result after impact test, (c) C-Scan result after second-stage fatigue test.

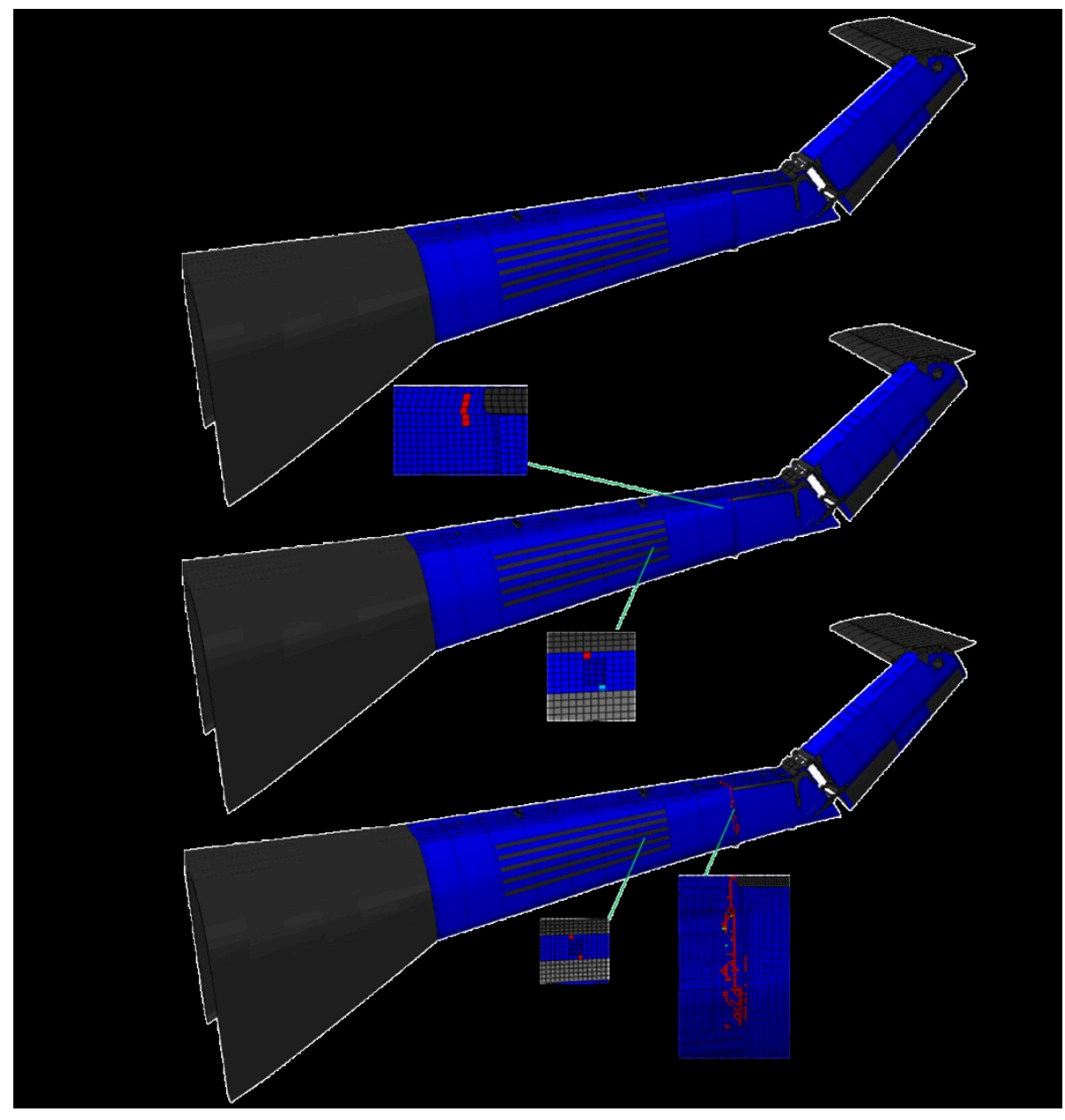


Fig. 16 Damage propagation of composite tail structure under multipoint spectrum loading: (a) undamaged structure after 48 repeated applications of the load spectrum, (b) damage state after 54 (or 48+6) repeated applications of the load spectrum, (c) damage state after 64(or 48+16) repeated applications of the load spectrum.

Table 1 Mechanical properties of metallic materials in tail structure ${ }^{[26]}$

\begin{tabular}{|c|c|c|c|}
\hline Material & $E / \mathrm{GPa}$ & $\mu$ & $\sigma_{b} / \mathrm{MPa}$ \\
\hline 2618 Aluminum alloy & 74 & 0.33 & 390 \\
\hline 7050 Aluminum alloy & 71 & 0.33 & 475 \\
\hline Ti-6Al-4V Titanium alloy & 110 & 0.31 & 1034 \\
\hline D6AC Low-alloy steel & 200 & 0.32 & 1544 \\
\hline
\end{tabular}

Table 2 Mechanical properties of composite materials in tail structure ${ }^{[27,28]}$

\begin{tabular}{|c|c|c|c|c|c|c|c|c|}
\hline Material & Type & $t / \mathrm{mm}$ & $\begin{array}{c}E_{11} / \\
\mathrm{GPa}\end{array}$ & $\begin{array}{c}E_{22} / \\
\mathrm{GPa}\end{array}$ & $\begin{array}{c}\mu_{12} \\
G_{12} / \\
\mathrm{GPa}\end{array}$ & $\begin{array}{c}G_{13} / \\
\mathrm{GPa}\end{array}$ & $\begin{array}{c}G_{23} / \\
\mathrm{GPa}\end{array}$ \\
\hline $3238 \mathrm{~A} / \mathrm{CF} 3052$ & Woven & 0.36 & 66.0 & 65.6 & 0.083 & 2.08 & 1.89 & 1.89 \\
\hline $3238 \mathrm{~A} / \mathrm{CCF} 300$ & $\mathrm{UD}$ & 0.14 & 131.0 & 9.64 & 0.29 & 4.74 & 4.74 & 2.95 \\
\hline
\end{tabular}

Table 3 Mechanical properties of honeycomb core composites in tail structure ${ }^{[29]}$

\begin{tabular}{|c|c|c|c|c|c|c|c|c|}
\hline Material & $t / \mathrm{mm}$ & $E_{11} / \mathrm{MPa}$ & $E_{22} / \mathrm{MPa}$ & $E_{33} / \mathrm{MPa}$ & $\mu_{12}$ & $G_{12} / \mathrm{MPa}$ & $G_{13} / \mathrm{MPa}$ & $G_{23} / \mathrm{MPa}$ \\
\hline Nomex & 2 & 0.0746 & 0.0746 & 121.86 & 0.9995 & 0.00329 & 20.688 & 13.066 \\
\hline
\end{tabular}

Table 4 Stacking sequences of composite parts in tail beam structure

\begin{tabular}{|c|c|c|}
\hline \multirow{2}{*}{ Structure } & \multicolumn{2}{|c|}{ Stacking sequence } \\
\hline \multirow{2}{*}{ frames T2 to T9 } & \multicolumn{2}{|c|}{$\left[( \pm 45) / 0_{2} /(0,90)\right]_{\mathrm{s}}$} \\
\hline \multirow{2}{*}{ Top wall } & Between frames T1 and T3 & Rest parts \\
\cline { 2 - 3 } & {$\left[( \pm 45) / 0_{3} /( \pm 45) / 0_{3} /(0,90)\right]_{\mathrm{s}}$} & {$\left[( \pm 45) / 0_{3} /(0,90)\right]_{\mathrm{s}}$} \\
\hline \multirow{2}{*}{$\begin{array}{c}\text { Left-side and } \\
\text { right-side walls }\end{array}$} & Between frames T1 and T2 & Rest parts \\
\cline { 2 - 3 } Bottom skin & {$\left[( \pm 45) / 0_{2} /( \pm 45) / 0_{2} /(0,90)\right]_{\mathrm{s}}$} & {$\left[( \pm 45) / 0_{2} /(0,90)\right]_{\mathrm{s}}$} \\
\cline { 2 - 3 } & {$\left[( \pm 45) / 0_{3} /( \pm 45) / 0_{3} /(0,90)\right]_{\mathrm{s}}$} & {$\left[( \pm 45) / 0_{3} /(0,90)\right]_{\mathrm{s}}$} \\
\hline \multirow{2}{*}{ Stringers } & \multicolumn{2}{|c|}{$\left[( \pm 45) / 0_{2} /( \pm 45) / 0 /( \pm 45) / 0\right]_{\mathrm{s}}$} \\
\hline middle and & {$\left[( \pm 45) / 0_{2} /( \pm 45) / 0 /(0,90) / 0 /( \pm 45) / 0 / \mathrm{C}_{10} / 0 /( \pm 45)\right]$} \\
\hline
\end{tabular}


end sidewalls

Table 5 Multipoint loads under left yawing and two-point horizontal landing conditions.

\begin{tabular}{|c|c|c|c|c|c|}
\hline \multirow{2}{*}{ Location } & \multirow{2}{*}{ Coordinates / mm } & \multicolumn{2}{|c|}{ Left yawing } & \multicolumn{2}{c|}{ Two-point horizontal landing } \\
\cline { 3 - 6 } & & Load / N & Direction & Load / N & Direction \\
\hline \multirow{2}{*}{ P1 } & \multirow{2}{*}{$(14650,0,1616)$} & -2370 & $F_{\mathrm{y}}$ & 0 & $F_{\mathrm{y}}$ \\
\cline { 3 - 6 } & & -4914 & $F_{\mathrm{z}}$ & -11827 & $F_{\mathrm{z}}$ \\
\hline \multirow{2}{*}{ P2 } & $(18085,-250,3465)$ & 20453 & $F_{\mathrm{y}}$ & 0 & $F_{\mathrm{y}}$ \\
\cline { 3 - 6 } & & -5118 & $F_{\mathrm{z}}$ & -18680 & $F_{\mathrm{z}}$ \\
\hline P3 & $(18085,1151,3075)$ & 1543 & $F_{\mathrm{x}}$ & 1542 & $F_{\mathrm{x}}$ \\
\cline { 3 - 6 } & & -7655 & $F_{\mathrm{z}}$ & 0 & $F_{\mathrm{z}}$ \\
\hline
\end{tabular}

Table 6 Strain gauge locations on strain measuring sections (unit: $\mathrm{mm}$ ).

\begin{tabular}{|c|c|c|c|c|}
\hline Strain gauge No. & S1 & $\mathrm{S} 2$ & S3 & S4 \\
\hline 1 & $(\mathrm{Y} 218, \mathrm{Z1990})$ & $(Y 230, \mathrm{Z} 1990)$ & (Y271, Z1990) & $(\mathrm{Y} 288, \mathrm{Z1990})$ \\
\hline 2 & $(\mathrm{Y} 310, \mathrm{Z1760)}$ & (Y354, Z1775) & (Y558, Z1701) & $(\mathrm{Y} 670, \mathrm{Z1688})$ \\
\hline 3 & (Y299, Z1401) & (Y375, Z1380) & (Y690, Z1191) & $(Y 817, \mathrm{Z1133})$ \\
\hline 4 & $(\mathrm{Y} 130, \mathrm{Z1285})$ & (Y164, Z1253) & (Y428, Z1235) & (Y485, Z1097) \\
\hline 5 & $(\mathrm{Y}-130, \mathrm{Z} 1285)$ & (Y-164, Z1253) & $(\mathrm{Y}-428, \mathrm{Z1235})$ & (Y-485, Z1097) \\
\hline 6 & $(\mathrm{Y}-299, \mathrm{Z1401})$ & $(\mathrm{Y}-375, \mathrm{Z1380})$ & $(\mathrm{Y}-690, \mathrm{Z1191})$ & $(\mathrm{Y}-817, \mathrm{Z1133})$ \\
\hline 7 & $(\mathrm{Y}-310, \mathrm{Z} 1760)$ & (Y-354, Z1775) & $(\mathrm{Y}-558, \mathrm{Z1701})$ & $(\mathrm{Y}-670, \mathrm{Z1688})$ \\
\hline 8 & $(\mathrm{Y}-218, \mathrm{Z1959)}$ & $(\mathrm{Y}-230, \mathrm{Z1994})$ & $(\mathrm{Y}-271, \mathrm{Z1996})$ & (Y-288, Z1993) \\
\hline
\end{tabular}


Finite element modeling and fatigue life prediction of helicopter composite tail structure under multipoint coordinated loading spectrum

Wan, Ao-Shuang

Elsevier

Wan A-S, Xu Y-G, Xue L-H, et al., (2020) Finite element modeling and fatigue life prediction of helicopter composite tail structure under multipoint coordinated loading spectrum. Composite Structures, Volume 225, January 2020, Article number 112900

https://doi.org/10.1016/j.compstruct.2020.112900

Downloaded from Cranfield Library Services E-Repository 